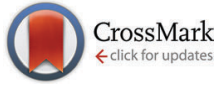

Cite this: J. Mater. Chem. B, 2017, 5, 1658

Received 7th October 2016 , Accepted 23rd January 2017

DOI: 10.1039/c6tb02612e

rsc.li/materials-b

\section{Growth behaviour of silica/carbonate nanocrystalline composites of calcite and aragonite $\dagger$}

\author{
Gan Zhang, Juan Morales and Juan Manuel García-Ruiz*
}

\begin{abstract}
The precipitation of barium and strontium carbonate in alkaline silica gels or silica solutions produces nanocrystalline self-assembled composite materials displaying biomimetic shapes and textures. We have crystallized concomitantly in time and space two anhydrous polymorphs of calcium carbonate, under similar conditions at different temperatures. The orthorhombic phase aragonite produces nanocrystalline aggregates exhibiting non-crystallographic morphologies and complex textures characteristic of silica biomorphs. Conversely, the simultaneously forming trigonal phase, calcite, yields rhombohedral crystals that experience fibrous growth and that maintain memory of the point symmetry group of the crystalline structure. Experiments performed at different temperatures (room temperature, 45, 60 and $80{ }^{\circ} \mathrm{C}$ ) revealed that the higher the temperature the higher the aragonite/calcite precipitation ratio, but the crystallization of calcite was never fully inhibited. We have studied the growth mechanism, the growth texture and the morphogenesis for both cases. We have found that the dramatic difference between the crystallization behaviours of the two mineral phases is due to the difference in the growth mechanism at the nanoscale.
\end{abstract}

\section{Introduction}

The ability of inorganic matter to mimic the morphology and texture of mineral or organic structures of living organisms is of both academic and technological interest. The technological interest arises from the superior microscopic and macroscopic physical properties displayed by biominerals and biochemical structures produced by living systems. ${ }^{1,2}$ The imitation of these structures has inspired many in vitro studies throughout recent years, by using biological macromolecules or different kinds of surfactants to induce hybrid biomineral-like composites, especially calcium carbonate, one of the most abundant biominerals. ${ }^{3-7}$ In addition to these bioroutes directed by organic molecules, recently there has been increasing interest in the exploration of biomimetic structures synthetized by inorganic-inorganic precipitation processes, especially in silica carbonate biomorphs. ${ }^{8-12}$

Silica biomorphs are purely inorganic nanocrystalline selforganized composite materials, displaying non-crystallographic morphologies and complex hierarchical textures that are strongly

Laboratorio de Estudios Cristalográficos, Instituto Andaluz de Ciencias de la Tierra (CSIC-UGR), Avenida de las Palmeras 4, E-18100 Armilla, Granada, Spain.

E-mail: jmgruiz@ugr.es; Fax: +34 958 552620; Tel: +34958230000

$\dagger$ Electronic supplementary information (ESI) available: Details of phase characterization (Fig. S1 and S2), analysis of chemical composition (Fig. S3), experiments on the temperature effect (Fig. S4), FESEM images of aragonite biomorphs (Fig. S5), and the time-lapse video of the growth of calcite and aragonite (Video S1). See DOI: 10.1039/c6tb02612e reminiscent of biominerals and biomimetic hybrid organic/ inorganic composites. ${ }^{13-15}$ They form by the coupling of silicic and carbonate chemistry during the precipitation of metal carbonate from alkaline ( $\mathrm{pH}$ 9-10.6) silica-rich solutions under current atmospheric conditions. Classically, silica biomorphs have been synthetized with orthorhombic barium carbonate (witherite) and strontium carbonate (strontianite). ${ }^{8,16-20}$ Recently it has also been shown that aragonite - the orthorhombic phase of calcium carbonate ${ }^{21-23}$ - and monohydrocalcite - the hexagonal monohydrate of calcium carbonate - also yield biomorphic structures (from G. Zhang et al., submitted). However, calcite, the hexagonal phase of calcium carbonate, always grows from alkaline silica-rich solution as crystals and crystal aggregates that preserve crystallographic symmetry and has been found to be reluctant to undergo biomorphic behaviour. ${ }^{24-26}$

In this study we report the simultaneous precipitation of aragonite and calcite crystals in silica gel under ambient conditions at different temperatures. Aragonite displays fascinating complex biomorphic morphologies including diabolo-like, flower-like and helicoids, while calcite exhibits single-crystal rhombohedra and skeletal morphologies that withhold the symmetry of the crystallographic structure. By studying at different length scales the texture of both types of structures we reveal the growth mechanism and the morphogenesis of these structures. Experiments performed at different temperatures reveal that the higher the temperature the higher the aragonite/calcite precipitation ratio, although complete inhibition of calcite has not been observed. 


\section{Experimental section}

Calcium carbonate crystals were produced by the counterdiffusion method in an alkaline silica gel. ${ }^{27-29}$ The experiments were performed in glass cassettes made by two flat glasses separated by a rubber ribbon with an inner volume of $4 \mathrm{~mL}$. The inner dimensions of the cassette are $100 \mathrm{~mm}$ in length, $40 \mathrm{~mm}$ in width, and $1 \mathrm{~mm}$ of thickness. The crystallization cell is used as a test tube with flat glass walls for easy optical visualization. The sodium carbonate containing alkaline silica sol was prepared by dissolving $1.39 \mathrm{~g}$ of sodium silicate in $9 \mathrm{~mL}$ of $0.2 \mathrm{M}$ sodium carbonate solution. Then the resulting sol was acidified by $3.5 \mathrm{~mL}$ of $1 \mathrm{M}$ hydrochloric acid solution for gelling. The concentration of calcium chloride solution was also $0.2 \mathrm{M}$.

For gelling, $2 \mathrm{~mL}$ of the above-described silica sol was injected in the lower part of the glass cassette. The waiting time was one week with a final gel $\mathrm{pH}$ of $10.5 \pm 0.1$. After this time, the $0.2 \mathrm{M}$ calcium chloride solution was injected into the cell on top of the gel, up to filling the growth cell. The injection of calcium chloride is considered as the time zero of the crystallization time scale. The experiments were carried out at four different temperatures, which were room temperature $\left(22{ }^{\circ} \mathrm{C} \pm 2\right), 45{ }^{\circ} \mathrm{C}, 60{ }^{\circ} \mathrm{C}$ and $80{ }^{\circ} \mathrm{C}$. The silica gel and the calcium chloride solution were prepared at room temperature but were stored overnight in a thermostatted oven at the corresponding temperature. After one night, the calcium chloride solution was injected into the cell on top of the silica gel and then stored in the oven. The crystallization process took place for three weeks. The experiment was repeated more than 100 times to test reproducibility.

The precipitates were examined in situ by Raman microspectroscopy using a LabRAM-HR spectrometer connected to a microscope. The Raman spectra were acquired by using a LabRAM-HR spectrometer attached to a microscope (Jobin-Yvon, Horiba, Japan). The excitation line was provided by a diode laser emitting at a wavelength of $532 \mathrm{~nm}$ and a Peltier cooled chargecouple device $(\mathrm{CCD})(1064 \times 256$ pixels) was used as the detector. The crystallization process was also recorded using a time-lapse optical microscope (Nikon AZ100) equipped with a CCD camera, using ImageJ software. Upon finishing the experiments, the crystalline particles were studied by field-emission scanning electron microscopy (FESEM) with an AURIGA (Carl Zeiss SMT) system. Energy dispersive X-ray (EDX) analysis that associated with FESEM was also performed to determine the chemical composition of calcium and silica. Furthermore, the particles were also crumbed into powder for the observation with high resolution transmission electron microscopy (HR-TEM) by using an FEI Titan at an acceleration voltage of $300 \mathrm{kV}$.

\section{Results and discussion}

\subsection{Growth history}

The diffusion of the calcium chloride into the carbonate-rich alkaline gel starts as soon as the solution is poured on top of the gel, and further provokes a chemical gradient that evolves in time and space. As a result, this chemical gradient induces temporal and spatial variation of $\mathrm{Ca} / \mathrm{CO}_{3}$ ratios as well as the $\mathrm{CaCO}_{3}$ supersaturation values, and thus yields calcium carbonate precipitation with different crystalline phases and morphologies at corresponding locations along the crystallization cell (Fig. 1). In fact, upon reaction of calcium and carbonate, the critical supersaturation with respect to $\mathrm{CaCO}_{3}$ was reached near the gel-solution interface and the first precipitate formed inside the gel. The first precipitates to nucleate and grow were rhombohedral crystals (Fig. 1a and 2a). The precipitation front advanced across the gel with time, the size of the rhombohedra increasing as a function of time and distance to the interface (Fig. 1b and c). This precipitation occurred in most cases as precipitation bands that follow the Jablczinsky law characteristic of Liesegang patterns (Fig. 1a). ${ }^{30,31}$ During the second week of crystallization, when the precipitation front had already advanced one centimetre from the gel-solution interface, these elongated calcite crystals developed into fibrous dendritic aggregates (Fig. $2 \mathrm{~b}$ and c). ${ }^{24,25}$ Then, interestingly, precipitates with complex biomorphic shapes appeared intermingled with the elongated fibrous calcite (Fig. 1b, $\mathrm{d}$ and e). These structures were confined to the zone between $1 \mathrm{~cm}$ and $2.5 \mathrm{~cm}$ from the gel-liquid interface, while the precipitation zone of elongated fibrous calcite advanced further in the gel during the third week of the experiment (Fig. $1 \mathrm{~b}$ and c).

\subsection{Phase characterization}

The flower-like biomorphs were identified as aragonite by synchrotron X-ray diffraction (Fig. S1, ESI $\dagger$ ). ${ }^{32}$ Additionally, several biomorphic structures were harvested and stored at room temperature for two months and then analysed with a Bruker X8 PROTEUM X-ray diffractometer, which confirmed the identification as aragonite (Fig. S1, ESI $\dagger$ ). In order to discard post-crystallization polymorphic transformation, the biomorphic structures were characterized in situ by Raman microspectroscopy (Fig. S2, ESI $\dagger$ ). The spectra showed that the core of the biomorphic structure, the cardioid laminar sheets, and the filaments were all made by aragonite with typical symmetric stretching $\left(\nu_{1}\right)$ at $1084 \mathrm{~cm}^{-1}$, in-plane bending mode $\left(\nu_{4}\right)$ at 700 and $705 \mathrm{~cm}^{-1}$, and lattice mode at 152 and $205 \mathrm{~cm}^{-1} \cdot 33$ The analysis of the chemical composition of the nanorods of the flower-like biomorphs as measured by EDX revealed the presence of $\mathrm{Ca}, \mathrm{Si}, \mathrm{C}$, and $\mathrm{O}$ (Fig. S3, ESI $\dagger$ ).

Parallel experiments performed at higher temperatures revealed that the mass ratio of aragonite/calcite increased with temperature in the range of 45 to $80{ }^{\circ} \mathrm{C}$, but fibrous calcite always appeared at all temperatures. Temperature also affected the morphology of silica aragonite biomorphs, as they formed smaller dumbbell-shaped cores and longer and larger petal-like curling sheets with more twisted and longer structures at higher temperatures (Fig. S4, ESI $\dagger$ ).

\subsection{Morphogenesis of calcite and aragonite silica/carbonate composites}

As described above, the morphologies displayed by calcite- and aragonite-made precipitates were so different from one another that they could be used as a proxy for mineral identification. The morphology of rhombohedra and fibrous calcite was controlled 


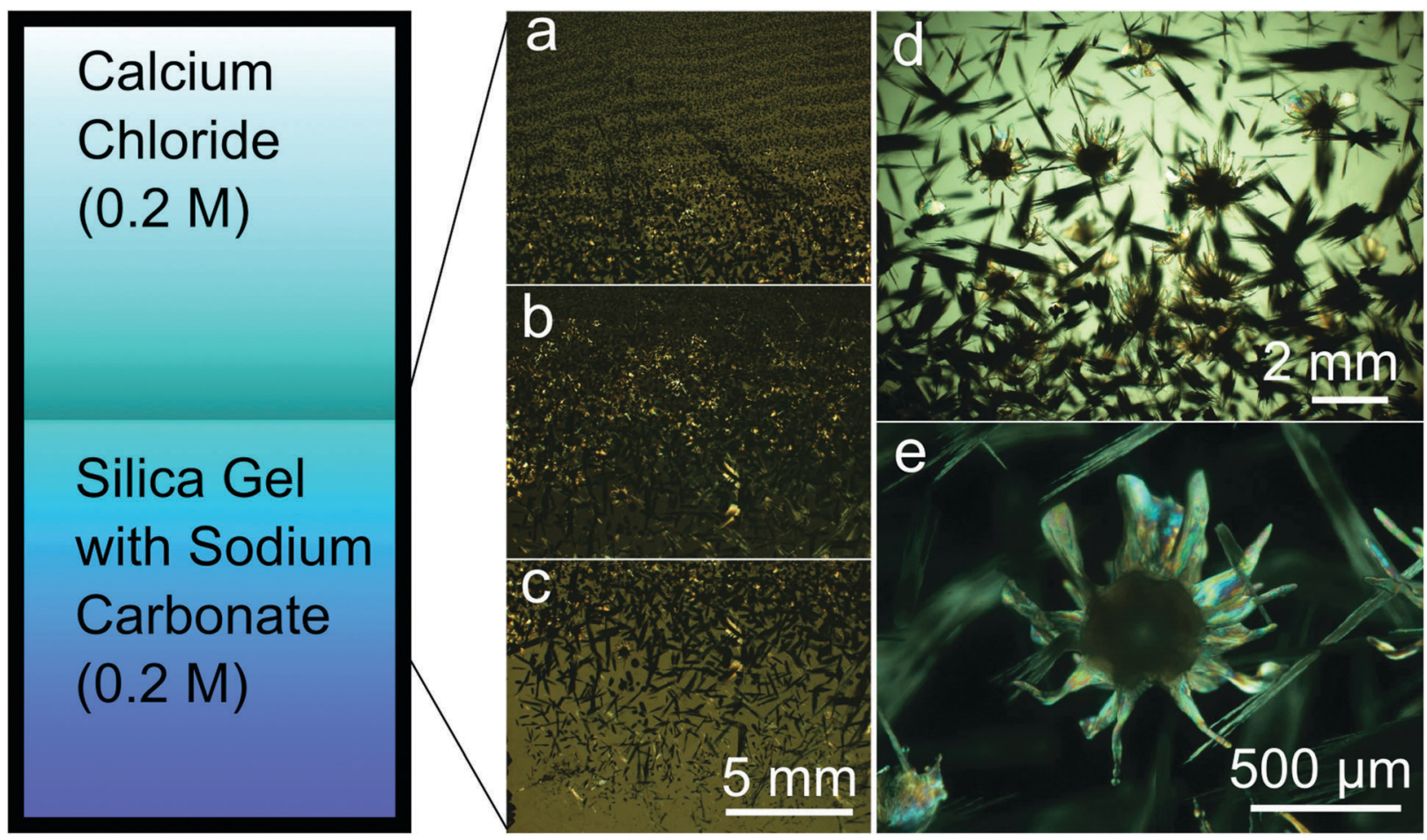

Fig. 1 Scheme of the experimental setup and the optical micrographs of the various crystal formation mechanisms after three weeks of crystallization. (a) Liesegang patterns of rhombohedral calcite; (b) concomitant crystallization of flower-like silica aragonite biomorphs and elongated calcite; (c) elongated calcite; ( $d$ and e) close-up view of flower-like silica aragonite biomorphs and elongated calcite.

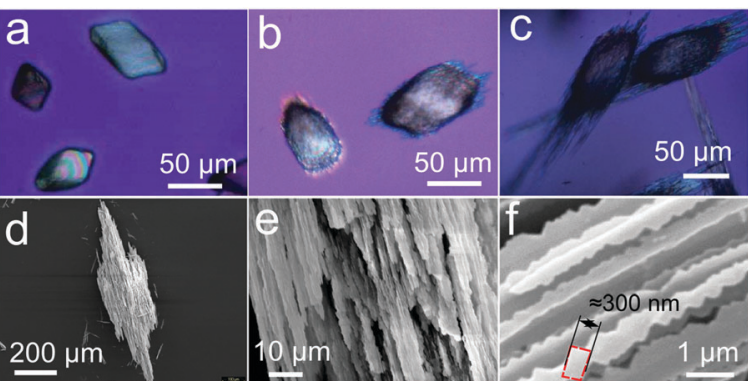

Fig. 2 (a) Optical micrograph of rhombohedra calcite crystallized near the gel-liquid interface; ( $b$ and $c$ ) optical micrograph of elongated fibrous calcite crystallized at 5 days and 10 days; (d) FESEM image of a full view of elongated fibrous calcite; (e and f) close-up view of elongated fibrous calcite.

by the crystal structure and therefore the crystallographic point symmetry was preserved and identifiable at different scales. However, the complex shapes of the precipitates made by aragonite were non-crystallographic. Thus, it was possible to optically identify both mineral patterns without the need for X-ray or Raman analysis. An astonishing example is shown in the time-lapse Video S1 (see the ESI $\dagger$ ) as well as in the frames of that video shown in Fig. 3. They show the concomitant growth of two different mineral phases, one clearly made of calcite and the other clearly made of aragonite. Two main observations are worth noting: (i) the strong difference in morphology shown by the two polymorphic calcium carbonate phases, and (ii) the simultaneous growth of both polymorphs under the same chemical conditions. As shown in Fig. 3, the distance between the calcite crystal and the edge of petal-like aragonite was $225 \mu \mathrm{m}$ (Fig. 3a), and it decreased during the growth of both crystalline structures to reach a distance shorter than $100 \mu \mathrm{m}$ at the end of the growth process (Fig. 3d). From the frames of the video shown in Fig. 3, it would appear that the calcite crystals had already nucleated once the aragonite biomorph was growing but, in general, there was no sequence observed in the formation of these mineral patterns. Actually, they grew intermingled with each other. These results challenge what is known about polymorphism because it is hard to assume a $\mathrm{pH}$ difference large enough to explain differences in silica species or calcium carbonate supersaturation. Further investigations are in progress to try to explain what controls polymorphism in this chemical environment. However, Video S1 (ESI $\dagger$ ) and Fig. 3 clearly show the inability of calcite to break crystal symmetry during growth and the ability of the orthorhombic aragonite to do so. Conversely, the growth of aragonite composites breaks the crystallographic symmetry and allows the structure to curl, forming helicoids and other non-crystallographic shapes with continuous curvature. We have found that the explanation is related to the texture of the forming composite at the nanoscale.

In the case of calcite, the starting rhombohedral crystals evolve into fibrous crystals composed of parallel-oriented fibres of micrometre-size thickness (Fig. 2). This evolution occurs by preferential growth of fibres tautozonal with the $c$-axis as shown in Fig. 2e and f. Higher magnification FESEM imaging reveals that the fibres have three-fold symmetry cross-section and a dentate shape substructure along the growth vectors. The three-fold 
a

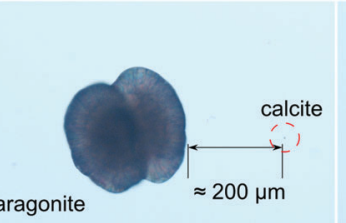

00:00:00

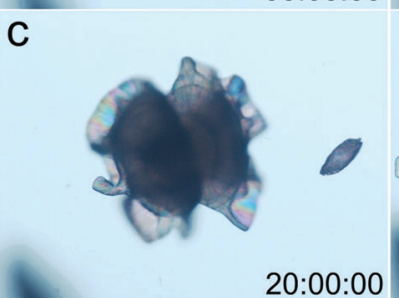

\section{b}

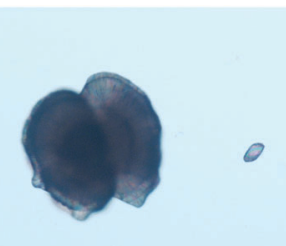

10:00:00

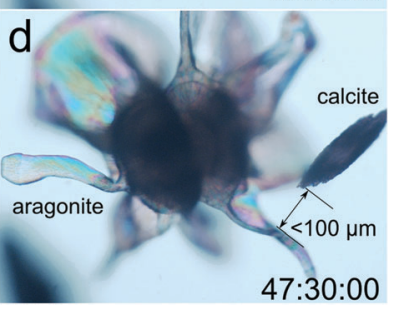

Fig. 3 Selected frames of the image sequence from the time-lapse video of the growth of flower-like silica aragonite biomorphs and elongated calcite (see the video in the ESI $\dagger$ ).

symmetry corresponds to selective inhibition of the growth faces of the cleavage rhombohedra $\{10-14\}$ along the hexagonal axes of the calcite structures. The dentate substructure is made of co-oriented crystallites of nearly rhombohedral shape with a size of approximately $300 \mathrm{~nm}$ (Fig. 2f). The fibres grow continuously without interruption during the whole growth history. No nucleation events can be distinguished because the calcite growth, albeit strongly affected by silicate absorption, is never fully arrested, as suggested by Imai and co-workers. ${ }^{21,26}$ Therefore the crystal always has memory of its own symmetry, i.e. there is no symmetry breaking and the precipitate cannot experience morphologies with point symmetry forbidden by the crystal structure. This observation agrees with the observation reported by Imai and co-workers.

Unlike the case of calcite, the biomorphic aragonite particles are formed by two or more conical surfaces joined at the apex, exhibiting a diabolo-like shape (Fig. 4a). In fact, the cones arise from the ends of an initial single crystal of aragonite. The adsorption of silica and silicate species provokes the splitting of the ends of the starting crystal. This creates fractal (noncrystallographic) dendrites with continuous growth that soon experience fibrillation, i.e. the complete inhibition of aragonite growth by silica and subsequent nucleation of new and independent aragonite crystallites. The self-feeding mechanism currently accepted for biomorphic growth starts to work: ${ }^{34}$ namely, there is a nucleation event of aragonite crystallites that decreases the $\mathrm{pH}$ and induces the precipitation of silica and silicate species that poison the crystal surfaces and eventually prevent further growth. The increase in $\mathrm{pH}$ due to silica precipitation provokes a new nucleation event of aragonite, which in turn provokes the fall in $\mathrm{pH}$, the corresponding precipitation of silica that inhibits their growth, and so on. Thus, the initial continuous fractal growth soon experiences fibrillation, i.e. the complete inhibition of the growth of the aragonite dendrite and subsequent nucleation of new and independent aragonite crystallites that grow only to hundreds of nanometres in size because of the poisoning by silica. The structure grows through the co-orientation of independent nanocrystals with no further memory of the crystal structure of the starting crystal.

The lips of the conical surfaces grew radially in twodimensions and experienced curling in several singular points. This led to changing the curvature, which converted the cones into petal-like sheets. ${ }^{34}$ Sometimes more than two conical surfaces arose from the apex and resulted in shapes with flower-like
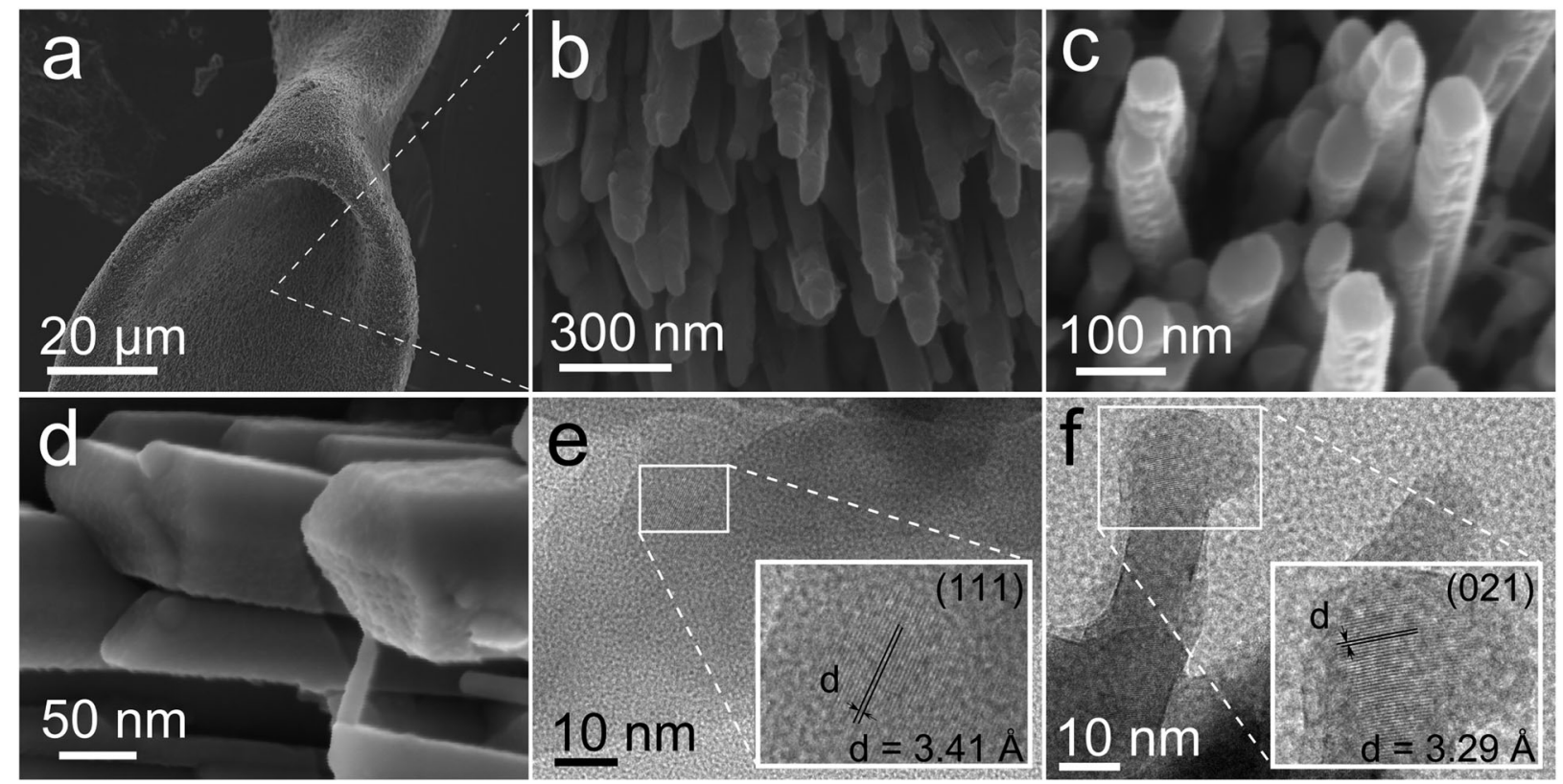

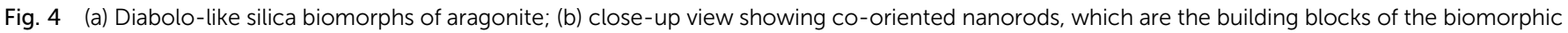

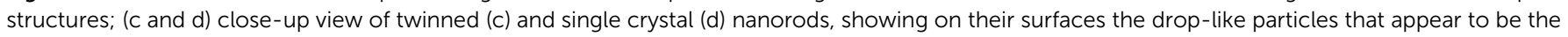
aggregation units for the growth mechanism; (e and f) TEM images of nano-size crystallites forming the nanorods of silica aragonite biomorphs. 
appearance (Fig. 1e). The rim of the laminar sheets kept on growing radially, showing concentric banding and adopting petal-like cardioid shapes (Fig. 1e). With time, some long filaments arose from singular points at the rim of the petal-like shape. These long filaments formed branches that may be ribbon-like, tentacle-like, tubular-like or helicoids (Fig. S5, ESI†). See also Video S1 in the ESI $\dagger$ for the micron to millimetre scale details of the growth of aragonite. These non-crystallographic morphologies displayed by aragonite are similar to classical barium carbonate and strontium carbonate biomorphs.

At the nanometre scale, the biomorphic aragonite structures consisted of densely packed needle-like crystallites or nanorods elongated along their $c$-axis. The nanorods are smaller than five hundred nanometres in length and fifty nanometres in width, with an aspect ratio (length/width) of approximately 7 . Fig. $4 \mathrm{~b}$ and $c$ are close-up views of different locations of the structure showing the co-orientation of the nanorods along the directions of the growing vectors. Higher magnification FESEM images reveal that these nanorods are in some cases twinned pseudo-hexagonal crystals exhibiting a tabular structure and crystallographic faces. This texture is very reminiscent of the nacre made of tabular crystals of aragonite in shells (Fig. 4c). ${ }^{35,36}$ In other cases the nanorods are single orthorhombic crystals with faceted phases. In none of these crystal faces is there evidence of two-dimensional nucleation, spiral growth or growth steps. However, many tiny rounded nanoparticles of less than ten nanometres in size can be observed on the crystal surface (Fig. 4d). Eiblmeier et al. have demonstrated using in situ potentiometric titration measurements and ex situ TEM and EDX that silica strongly affects barium carbonate crystallization up to fully arresting crystallization on the nanoscale. ${ }^{37}$ Thus, the building blocks of $\mathrm{BaCO}_{3}$ biomorphs are made of silica stabilized submicron $\mathrm{BaCO}_{3}$ nanocrystallites. Our TEM observations (Fig. 4e and f) indicate that in fact the nanorods of aragonite are also composed of tiny crystallites with an average size at $8.5 \mathrm{~nm}$ approximately, with detected d spaces of $3.41 \AA$ and $3.29 \AA$ corresponding to the (111) and (021) planes of aragonite. These observations indicate that the growth of the nanorods of aragonite takes place by accretion of nanoparticles, either amorphous or dense liquid particles, a growth mechanism already proposed for barium carbonate biomorphs and a characteristic feature of the growth of biominerals. ${ }^{37,38}$ In addition, the biomorphic aragonite particles formed at $80^{\circ} \mathrm{C}$ also consisted of densely packed nanorods (Fig. S4, ESI $\dagger$ ), which exhibited the same morphology and texture to the one formed at room temperature.

Fig. 5 schematically shows the different growth modes of biomorphic aragonite and non-biomorphic calcite, on the basis of the substantial difference in how silicates inhibit their growth. The calcite dentate fibre-like subunits grow continuously and therefore remain the consistent growth vectors. In contrast, the aragonite nanorod subunits that form due to the cessation of growth on the nanoscale are isolated, which allows gradual change of the growth vectors leading to the phenomenon of curling. Since the orthorhombic barium and strontium carbonates also exhibit biomorphic growth features like aragonite, one could conclude that the formation of biomorphs seems to be exclusive of

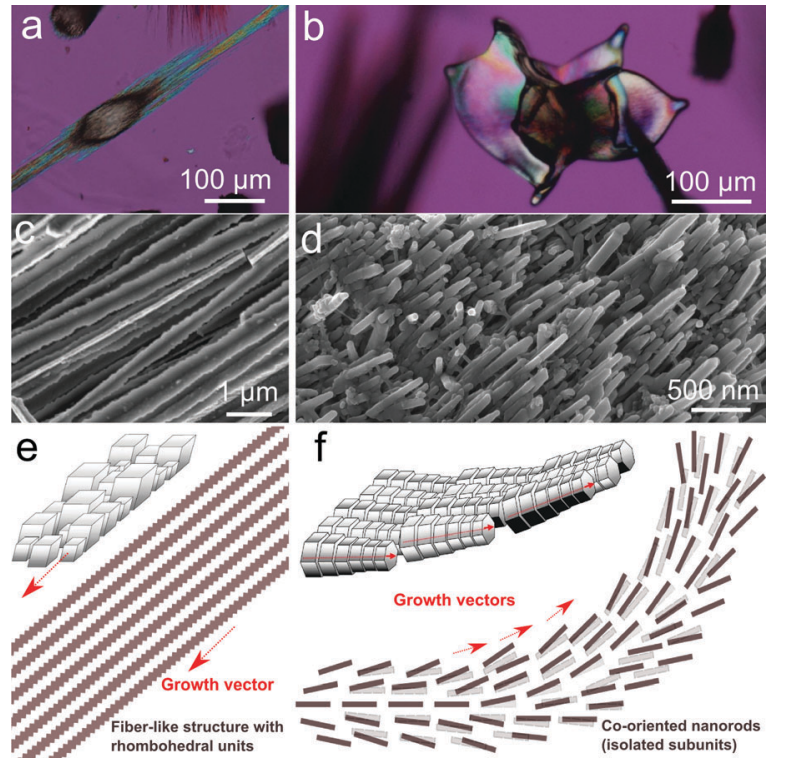

Fig. 5 (a) Non-biomorphic calcite and (b) biomorphic aragonite as seen by optical microscopy with crossed polarisers; (c) FESEM pictures of co-oriented fibres of non-biomorphic calcite and (d) nanorods forming biomorphic aragonite; (e) scheme of the textural model for non-biomorphic calcite and (f) biomorphic aragonite. Fibrillation of biomorphic aragonite allows the bending and curling of the composite material and then complex morphogenesis.

orthorhombic carbonates. However, the above results suggest that the morphogenesis of silica biomorphs is triggered only after the growth of the carbonates experiences fibrillation. This depends on the different effect of silica on the growth mechanism. While silicate species selectively inhibit growth faces of calcite but not total cessation of growth, they fully inhibit the growth of aragonite provoking new nucleation events and fibrillation. The discovery that monohydrocalcite, the hexagonal hydrate of $\mathrm{CaCO}_{3}$, can also display typical biomorphic morphologies confirms that biomorphic behaviour is not exclusive to a given crystal structure. ${ }^{39}$ Eiblmeier et $a l^{40}$ demonstrated that a small percentage of Ca ions inhibit the biomorphic growth of barium carbonate ( $2 \mathrm{~mol} \%$ ) and strontium carbonate $(10 \mathrm{~mol} \%)$. They suggested that this is due to the stronger interaction of $\mathrm{Ca}^{2+}$ ions and silicate species in solution with respect to $\mathrm{Ba}^{2+}$ and $\mathrm{Sr}^{2+}$. However, the fact that biomorphic and non-biomorphic structures of calcium carbonate can form simultaneously in the same chemical solution rather suggests that the explanation must be due to how easily silicates polymerize on the different growth surface configurations offered by the different polymorphs of calcium carbonate.

\section{Conclusions}

We have demonstrated that calcite and aragonite, the two main polymorphs of calcium carbonate, may adopt completely different growth behaviours at the nanoscale in the presence of silica at high $\mathrm{pH}$. While calcite adopts rhombohedral and fibrous shapes elongated along the $c$-axis that preserve the crystallographic continuity and symmetry, aragonite displays non-crystallographic 
biomimetic shapes, which are built by co-oriented nanocrystals that self-assemble exhibiting hierarchically ordered micro- and nanostructures. The morphogenesis of the complex shapes displayed by biomorphic aragonite is explained as the result of the curling mechanism. ${ }^{34}$ The dramatic difference between the two polymorphs is not related to their crystal structure but to the texture at the nanoscale, since biomorphic aragonite particles consist of nanorods while fibrous elongated calcite particles consist of rhombohedral crystallites. Both phases were grown concomitantly under ambient conditions within a gel of silica under alkaline $\mathrm{pH}$. This experimental set-up has allowed us to show dramatically the different growth and morphological behaviour of the two $\mathrm{CaCO}_{3}$ polymorphs.

\section{Acknowledgements}

The research leading to these results has received funding from the European Research Council under the European Union's Seventh Framework Programme (FP7/2007-2013)/ERC grant agreement no. 340863. G. Zhang acknowledges the Spanish Consejo Superior de Investigaciones Científicas for the pre-doctoral fellowship, within the programme "Junta para la Ampliación de Estudios". The authors also acknowledge Alicia González Segura from the Centre of Scientific Instrumentation of the University of Granada for her technical assistance.

\section{Notes and references}

1 H. A. Lowenstam and S. Weiner, On Biomineralization, Oxford University Press, 1989.

2 S. Mann, Biomineralization: Principles and Concepts in Bioinorganic Materials Chemistry, Oxford University Press, 2001.

3 K. M. Wilbur and A. M. Bernhardt, Biol. Bull., 1984, 166, 251-259.

4 J. J. J. M. Donners, B. R. Heywood, E. W. Meijer, R. J. M. Nolte, C. Roman, A. P. H. J. Schenning and N. A. J. M. Sommerdijk, Chem. Commun., 2000, 1937-1938.

5 S. G. Deng, J. M. Cao, J. Feng, J. Guo, B. Q. Fang, M. B. Zheng and J. Tao, J. Phys. Chem. B, 2005, 109, 11473-11477.

6 A. S. Finnemore, M. R. J. Scherer, R. Langford, S. Mahajan, S. Ludwigs, F. C. Meldrum and U. Steiner, Adv. Mater., 2009, 21, 3928-3932.

7 X. Zhang, Z. Fan, Q. Lu, Y. Huang, D. L. Kaplan and H. Zhu, Acta Biomater., 2013, 9, 6974-6980.

8 M. Kellermeier, H. Cölfen and J. M. García-Ruiz, Eur. J. Inorg. Chem., 2012, 5123-5144.

9 W. L. Noorduin, A. Grinthal, L. Mahadevan and J. Aizenberg, Science, 2013, 340, 832-837.

10 G. Wang, X. Zhao, M. Möller and S. E. Moya, ACS Appl. Mater. Interfaces, 2015, 7, 23412-23417.

11 J. Opel, F. P. Wimmer, M. Kellermeier and H. Colfen, Nanoscale Horiz., 2016, 1, 144-149.

12 E. Nakouzi and O. Steinbock, Sci. Adv, 2016, 2, e1601144.

13 J. M. García-Ruiz, S. T. Hyde, A. M. Carnerup, A. G. Christy, M. J. Van Kranendonk and N. J. Welham, Science, 2003, 302, 1194-1197.
14 S. T. Hyde, A. M. Carnerup, A.-K. Larsson, A. G. Christy and J. M. García-Ruiz, Phys. A, 2004, 339, 24-33.

15 M. Kellermeier, E. Melero-García, F. Glaab, J. Eiblmeier, L. Kienle, R. Rachel, W. Kunz and J. M. García-Ruiz, Chem. - Eur. J., 2012, 18, 2272-2282.

16 J. M. García-Ruiz and J. L. Amorós, J. Cryst. Growth, 1981, 55, 379-383.

17 J. M. Garcia-Ruiz, J. Cryst. Growth, 1985, 73, 251-262.

18 T. Terada, S. Yamabi and H. Imai, J. Cryst. Growth, 2003, 253, 435-444.

19 A. E. Voinescu, M. Kellermeier, A. M. Carnerup, A.-K. Larsson, D. Touraud, S. T. Hyde and W. Kunz, J. Cryst. Growth, 2007, 306, 152-158.

20 M. Kellermeier, F. Glaab, A. M. Carnerup, M. Drechsler, B. Gossler, S. T. Hyde and W. Kunz, J. Cryst. Growth, 2009, 311, 2530-2541.

21 H. Imai, T. Terada, T. Miura and S. Yamabi, J. Cryst. Growth, 2002, 244, 200-205.

22 A. E. Voinescu, M. Kellermeier, B. Bartel, A. M. Carnerup, A.-K. Larsson, D. Touraud, W. Kunz, L. Kienle, A. Pfitzner and S. T. Hyde, Cryst. Growth Des., 2008, 8, 1515-1521.

23 E. Bittarello, F. Roberto Massaro and D. Aquilano, J. Cryst. Growth, 2010, 312, 402-412.

24 S. Dominguez Bella and J. M. Garcia-Ruiz, J. Cryst. Growth, 1986, 79, 236-240.

25 S. Domínguez-Bella and J. Garcia-Ruiz, J. Mater. Sci., 1987, 22, 3095-3102.

26 H. Imai, T. Terada and S. Yamabi, Chem. Commun., 2003, 484-485.

27 E. Melero-García, R. Santisteban-Bailón and J. M. García-Ruiz, Cryst. Growth Des., 2009, 9, 4730-4734.

28 G. Zhang, J. M. Delgado-Lopez, D. Choquesillo-Lazarte and J. M. Garcia-Ruiz, CrystEngComm, 2013, 15, 6526-6532.

29 G. Zhang, J. M. Delgado-López, D. Choquesillo-Lazarte and J. M. García-Ruiz, Cryst. Growth Des., 2015, 15, 564-572.

30 E. Schönherr, Adv. Mater., 1989, 1, 91-92.

31 K. Jablczynski, Bull. Soc. Chim. Fr., 1923, 33, 1592.

32 J. P. R. de Villiers, Am. Mineral., 1971, 56, 758-767.

33 C. G. Kontoyannis and N. V. Vagenas, Analyst, 2000, 125, 251-255.

34 J. M. García-Ruiz, E. Melero-García and S. T. Hyde, Science, 2009, 323, 362-365.

35 S. Blank, M. Arnoldi, S. Khoshnavaz, L. Treccani, M. Kuntz, K. Mann, G. Grathwohl and M. Fritz, J. Microsc., 2003, 212, 280-291.

36 F. Barthelat, H. Tang, P. D. Zavattieri, C. M. Li and H. D. Espinosa, J. Mech. Phys. Solids, 2007, 55, 306-337.

37 J. Eiblmeier, U. Schurmann, L. Kienle, D. Gebauer, W. Kunz and M. Kellermeier, Nanoscale, 2014, 6, 14939-14949.

38 A. Gal, S. Weiner and L. Addadi, CrystEngComm, 2015, 17, 2606-2615.

39 G. Zhang, PhD thesis, Universidad International Menéndez Pelayo, 2015.

40 J. Eiblmeier, S. Dankesreiter, A. Pfitzner, G. Schmalz, W. Kunz and M. Kellermeier, Cryst. Growth Des., 2014, 14, 6177-6188. 